\title{
IS THERE TREATMENT EFFECT OF VINPOCETINE ON AUTONOMIC DYSFUNCTION IN RATS WITH ALZHEIMER?
}

\author{
NAZAN DOLU' ${ }^{1}$, SEDA GÜNDÜZ2 ${ }^{2}$, ALI YUCEL KARA ${ }^{2}$, HALE ACER ${ }^{2}$, SELDA TASAN ${ }^{2}$, AZIZUDDIN KHAN ${ }^{3}$
}

${ }^{1}$ Department of Physiology, Faculty of Medicine, Erciyes University, Kayseri, Turkey. ${ }^{2}$ Department of Physiology, Institute of Health Sciences, Erciyes University, Kayseri, Turkey. ${ }^{3}$ Department of Humanities and Social Sciences, Pschopysiology Laboratory, Indian Institute of Technology Bombay, Powai - 400 076, Mumbai, Maharashtra, India. Email: khanaziz@iitb.ac.in

Received: 21 February 2016, Revised and Accepted: 02 September 2016

ABSTRACT

Objective: Alzheimer's disease (AD) shows less autonomic dysfunction. There was a lack of response or prolongation of its latency in skin sympathetic response. Vinpocetine is a classic inhibitor of PDE1 activity. Vinpocetine treatment has been shown to enhance performance on cognitive tests in humans. The efficacy of the use of vinpocetine in clinical trials has been controversial. A comparison of multiple studies evaluating vinpocetine use in AD was recently conducted. Our first aim was to assess dysautonomia in rat with AD electrophysiologically, using sympathetic skin response (SSR) test. The second aim of this study, evaluate the effect of vinpocetine treatment on Alzheimer autonomic dysfunction and attention deficiency.

Methods: Rats were divided into four groups: Sham group (Group C, i.p. saline), Alzheimer group (Group A), vinpocetine group (Group V, 5 mg/kg, every other day, i.p.), Alzheimer+vinpocetine group (Group AV). AD was induced in old male rats by $\mathrm{AlCl}_{3} 40 \mathrm{mg} / \mathrm{kg}$ i.p.) and D-galactose (90 mg/kg) daily for 6 weeks. Then skin conductance level (SCL), which is an SSR parameter, was measured as tonic (no-stimuli period, 2 minutes) and phasic SSR (simultaneously with 15 auditory stimuli, 10 minutes). Tonic SSR is useful to investigate general states of arousal and alertness, while phasic SSR is useful to study multifaceted attentional processes (related to novelty, intensity).

Results: SCL was a difference among groups (tonic: $F=21.47, p \leq 0.000$; phasic: $F=9.86, p \leq 0.000$ ). SCL was statistically lower in Group A than Group C $(p \leq 0.005)$ and Group V ( $\leq 0.000)$. SCL of Group V was statistically higher than Group C ( $\leq \leq 0.04)$, Group A ( $\leq 0.000)$ and Group AV ( $\leq 0.000)$. SCL of Group AV was lower than Group C's ( $\mathrm{p} \leq 0.01)$.

Conclusion: There was no statistically difference between Group A and Group AV. We concluded that autonomic disturbances accompanied AD and vinpocetine treatment could not ameliorate this disturbance.

Keywords: Autonomic dysfunction, Dysautonomia, Inhibitor, Skin conductance level, Sympathetic skin response.

(C) 2017 The Authors. Published by Innovare Academic Sciences Pvt Ltd. This is an open access article under the CC BY license (http://creativecommons. org/licenses/by/4.0/) DOI: http://dx.doi.org/10.22159/ajpcr.2017.v10i2.11367

\section{INTRODUCTION}

Alzheimer's disease (AD) is a progressive neurodegenerative disorder associated with cognitive and behavioral dysfunction. It is the leading cause of dementia in the elderly [1]. AD is characterized by the progressive accumulation of amyloid beta peptide, neurofibrillary tangles,, and hyperphosphorylated microtubuleassociated tau protein. Several regions involved in memory and learning processes in the brain, such as the hippocampus, show neuron apoptosis several years before clinical signs appear [2]. AD also shows less autonomic dysfunction. The majority of patients presented with abnormalities in skin sympathetic response: Lack of response or prolongation of its latency. Idiaquez and Roman also showed less autonomic dysfunction in AD and frontotemporal lobar degeneration $[3,4]$.

In this study, our first aim was to assess dysautonomia in rat with $\mathrm{AD}$ electrophysiologically, using sympathetic skin response (SSR) test. One of the most widely used indices of the autonomic nervous system in psychological research has been SSR test or electrodermal activity (EDA), which is usually measured as skin conductance level (SCL) [5]. It is recorded as a change in skin potential or resistance of sweat gland reaction controlled by the sympathetic nervous system. SCL also reflects tonic levels of arousal [6]. SSR has been utilized in research examining attention, emotion, and psychopathology [7-11].

SSR was studied in Alzheimer to the evaluation of clinical and functional assessment of dysautonomia [4], to investigate sudomotor function [3], and to explore cardiovascular functions $[3,12]$. They found abnormal SSR test in humans. There are some studies investigate autonomic dysfunction in rats. However, none of them studied with SSR test.

It is now estimated that there are 18-24 million people suffering from AD worldwide. Today there is no cure for this devastating disease. Hence, it is of great interest for researchers to find new treatment that can hinder the disease process. Some drugs may improve the function of intact neurons, but do not inhibit degenerative process leading to neuronal cell death. The alkaloid vinpocetine is a classic inhibitor of PDE1 activity [2]. Vinpocetine treatment has been shown to improve memory retrieval, and enhance performance on cognitive tests in humans [13]. The efficacy of the use of vinpocetine in clinical trials has been controversial.

This is the first study explore autonomic function with SSR in rats with Alzheimer. We also evaluated the effect of vinpocetine treatment on Alzheimer autonomic dysfunction and attention deficiency.

\section{METHODS}

This study was carried out in Erciyes University Faculty of Medicine, Physiology Department, Kayseri, Turkey from September 2012 to September 2013. Thirty-two male Sprague-Dawley 19-month-old rats were included in the study. The experiments were performed in laboratories with standardized conditions at $22 \pm 2^{\circ} \mathrm{C}$ and $50 \pm 5 \%$ humidity. A standard diet and tap water were provided ad-libitum. All rats were bred at the Hakan Çetinsaya Experimental and Clinical 
Research Center of Erciyes University and were fed with tap water and Purina rodent chow. The experiments were carried out after receiving approval from the Committee on Ethics in Animal Experimentation at Erciyes University (No. 08-12-85). All animal experiments were conducted at Erciyes University Faculty of Medicine, Department of Physiology in the Laboratory of Brain Dynamics.

\section{Study protocol}

Rats were divided into four groups: Sham group (Group C, i.p. saline, $N=9$ ), Alzheimer group (Group $A, N=9$ ), Vinpocetine group (Group V, $5 \mathrm{mg} / \mathrm{kg}$, every other day, i.p., $\mathrm{N}=7$ ), Alzheimer+vinpocetine group (Group $\mathrm{AV}, \mathrm{N}=7$ ). $\mathrm{AD}$ was induced in old male rats by intraperitoneal administration of AlCl3 (40 mg/kg body weight) and D-Galactose ( $90 \mathrm{mg} / \mathrm{kg}$ body weight) daily for 6 weeks.

\section{SSR recordings}

SSR was measured using the MP30 system (MP30; Biopac Systems Inc., Santa Barbara, CA) and the physiological recordings took place in a dimly lit, electrically and acoustically shielded experimental room. Before the recordings, rats were subjected to a habituation period of 5 minutes. SSR was recorded, employing a constant voltage technique and sampling the absolute, direct current skin conductance at the rate of 20 samples per second, from the plantar surface of the posterior extremities of each rat using $\mathrm{Ag} / \mathrm{AgCl}$ electrodes. Animals were conscious during recording, and multipurpose gel was used between the skin and the electrodes. Electrodes were connected to the MP30 system. The incoming signals of skin response were converted to digital signals through an MP30 data acquisition unit and processed with offline analysis [5].

\section{Tonic SSR}

A period of 2 minutes was allowed at the start of recording to register non-specific SCL $\left(\mu \mathrm{mho} / \mathrm{cm}^{2}\right)$ during a no-stimuli period. Tonic SSR is useful to investigate general states of arousal and alertness.

\section{Phasic SSR}

The 15 auditory stimuli were presented at the end of the tonic EDA period (no-stimuli period). All were 1-s, $90 \mathrm{~dB}, 1000-\mathrm{Hz}$ tones with 50 -ms rise and fall times. They occurred at pseudo-random intervals ranging from 30 to 65 seconds, averaging 45 seconds. The mean SCL values were calculated also off-line for phasic SSR. Phasic SSR is useful to study multifaceted attentional processes (related to novelty, intensity).

\section{Statistical analyses}

Values were expressed as means \pm SE. Data from SSR recordings analyzed with the ANOVA test for comparison of the 4 groups and the post-hoc Scheffe test was used for comparison of 2 groups. Differences were considered to be significant with a $\mathrm{p}<0.05$. All the statistical analyses were performed using the SPSS 16.0 for Windows software.

\section{RESULTS}

Table 1 indicates the mean SCL values in all groups. SCL was a difference among groups (tonic: $\mathrm{F}=21.47, \mathrm{p} \leq 0.000$; phasic: $\mathrm{F}=9.86, \mathrm{p} \leq 0.000$ ). SCL was statistically lower in Group AD than Group C $(p \leq 0.005)$ and Group V ( $\leq 50.000)$ in tonic and phasic recordings. SCL of Group V was statistically higher than Group C $(p \leq 0.04)$, Group A $(p \leq 0.000)$ and Group AV $(p \leq 0.000)$ for tonic recordings. Tonic SCL of Group ADV was lower than Group C's ( $\mathrm{p} \leq 0.01$ ) (Fig. 1). There was no statistically difference between Group AD and Group ADV.

\section{DISCUSSION}

This is the first study investigating therapeutic effect of vinpocetine on sympathetic activity and autonomic dysfunction in AD. We found that vinpocetine was increased SSRs, but it was not therapeutically efficacious on Alzheimer's autonomic function.

The use of vinpocetine in animal models suggests that vinpocetine has a role to play in restoring neuronal plasticity (learning and memory
Table 1: Descriptives of SCL values of groups (mean \pm SE)

\begin{tabular}{lllll}
\hline $\begin{array}{l}\text { Skin } \\
\text { conductance } \\
\text { level }\end{array}$ & $\begin{array}{l}\text { Group C } \\
(\mathbf{n}=7)\end{array}$ & $\begin{array}{l}\text { Group AD } \\
(\mathbf{n}=6)]\end{array}$ & $\begin{array}{l}\text { Group V } \\
(\mathbf{n}=7)\end{array}$ & $\begin{array}{l}\text { Group ADV } \\
(\mathbf{n}=7)\end{array}$ \\
\hline Tonic & $10.70 \pm 0.28$ & $6.6 \pm 0.59$ & $13.8 \pm 0.58$ & $7.07 \pm 4.36$ \\
Phasic & $9.63 \pm 0.35$ & $5.25 \pm 0.48$ & $10.93 \pm 0.98$ & $6.66 \pm 1.20$ \\
\hline
\end{tabular}

SCL: Skin conductance level, Group C: Sham group; Group AD: Alzheimer group, Group V: Vinpocetine group; Group ADV: Alzheimer+Vinpocetine group, SE: Standard error

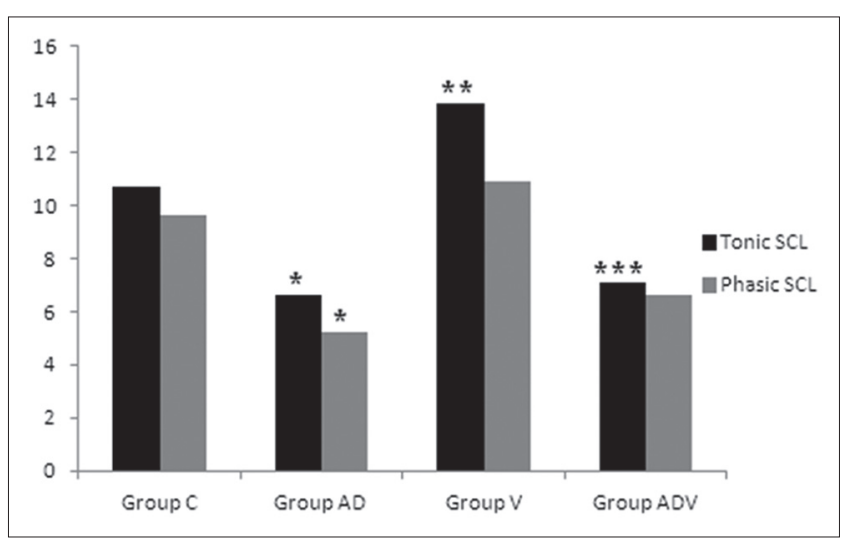

Fig. 1: Comparison of SCL values of groups. *Different from Group C and Group V; **versus Group ADV and Group C; ${ }^{* * *}$ versus Group C, SCL: Skin conductance level, Group C: Sham group, Group AD: Alzheimer group, Group V: Vinpocetine group, Group ADV: Alzheimer+vinpocetine group

in particular) in different conditions. However, the findings from clinical trials are still controversial, and more studies are needed. It is conceivable that one reason for this discrepancy is the great difference in the dosage used in basic science studies and the ones used in clinical trials. Most studies performed in animal models used doses between 10 and $20 \mathrm{mg} / \mathrm{kg}[14,15]$. These doses translated to humans would result in approximately $1,000 \mathrm{mg}$, which would be roughly a 20 -fold increase in the current doses used in clinicaltrials [16-18].

We found only one study related with vinpocetine and sympathetic system. Gaáland Molnár found that vinpocetine produces a significant and dose-dependent increase in the firing rate of locus coeruleus neurons [19]. They also claimed that vinpocetine increases the activity of ascending noradrenergic pathways and this effect can be related to the cognitive-enhancing characteristics of the compound.

\section{CONCLUSION}

We concluded that autonomic disturbances accompanied $\mathrm{AD}$ and vinpocetine treatment could not ameliorate this disturbance.

\section{ACKNOWLEDGMENT}

This study was supported by the Research Fund of the Erciyes University (TYL-2013-4227). We would like to thank Professor Seyfullah Korkmaz for arabic translation.

\section{REFERENCES}

1. Zhang X, Yin WK, Shi XD, Li Y. Curcumin activates Wnt/ $\beta$-catenin signaling pathway through inhibiting the activity of GSK-3 $\beta$ in APPswe transfected SY5Y cells. Eur J Pharm Sci 2011;42(5):540-6.

2. Pan R, Qiu S, Lu DX, Dong J. Curcumin improves learning and memory ability and its neuroprotective mechanism in mice. Chin Med J (Engl) 2008;121(9):832-9.

3. Paradowski B, Bilinska M, Koszewicz M, Pokryszko A. Evaluation of cardiovascular and sudomotor functions in Alzheimer's disease. Pol Merkur Lekarski 1999;7(40):180-4 
4. Zakrzewska-Pniewska B, Gawel M, Szmidt-Salkowska E, Kepczynska K, Nojszewska M. Clinical and functional assessment of dysautonomia and its correlation in Alzheimer's disease. Am J Alzheimers Dis Other Demen 2012;27(8):592-9.

5. Dolu N, Keloglan S, Bitiktas S, Cug S. The effects of the enriched environment on sympathetic skin response in pentylenetetrazol-kindled rats. Biomed Environ Sci 2013;26(5):394-7.

6. Edelberg R. Electrical activity of the skin: It smeasurement and uses in psychophysiology. In: Greenfield NS, Sternbach RS, editors. Handbook of Psychophysiology. New York, Holt: Rinehartand Winston; 1967. p. 367-418.

7. Andor T, Gerlach AL, Rist F. Superior perception of phasicphysiological arousal and the detrimental consequences of the conviction to be aroused on worrying and metacognitions in GAD. J Abnorm Psychol 2008;117(1):193-205.

8. Dawson ME, Schell AM, Filion DL, Berntson GG. The electrodermal system. Handbook of Psychophysiology. $3^{\text {rd }}$ ed. New York: Cambridge University Press; 2007. p. 159-81.

9. Naccache L, Dehaene S, Cohen L, Habert MO, Guichart-Gomez E, Galanaud D, et al. Effortless control: Executive attention and conscious feeling of mental effort are dissociable. Neuropsychologia 2005;43(9):1318-28.

10. Bradley MM, Codispoti M, Cuthbert BN, Lang PJ. Emotion and motivation I: Defensive and appetitive reactions in picture processing. Emotion 2001;1(3):276-98.
11. Strauman TJ. Self-discrepancies in clinical depression and social phobia: Cognitive structures that underlie emotional disorders? J Abnorm Psychol 1989;98(1):14-22.

12. Wang SJ, Liao KK, Fuh JL, Lin KN, Wu ZA, Liu CY, et al. Cardiovascular autonomic functions in Alzheimer's disease. Age Ageing 1994;23(5):400-4.

13. Filgueiras CC, Krahe TE, Medina AE. Phosphodiesterase Type 1 inhibition improves learning in rats exposed to alcohol during the third trimester equivalent of human gestation. Neurosci Lett 2010;473(3):202-7.

14. Medina AE, Krahe TE, Ramoa AS. Restoration of neuronal plasticity by a phosphodiesterase Type 1 inhibitor in a model of fetal alcohol exposure. J Neurosci 2006;26(3):1057-60.

15. Deshmukh R, Sharma V, Mehan S, Sharma N, Bedi KL. Amelioration of intra cerebroventricular streptozotocin induced cognitive dysfunction and oxidative stress by vinpocetine--a PDE1 inhibitor. Eur J Pharmacol 2009;620(1-3):49-56.

16. Szatmari SZ, Whitehouse PJ. Vinpocetine for cognitive impairment and dementia. Cochrane Database Syst Rev 2003;1:CD003119.

17. Bereczki D, Fekete I. Vinpocetine for acute ischaemic stroke. Cochrane Database Syst Rev 2009;23:CD000480.

18. Medina AE. Therapeutic utility of phosphodiesterase Type I inhibitors in neurological conditions. Front Neurosci 2011;5:21.

19. Gaál L, Molnár P. Effect of vinpocetine on noradrenergic neurons in rat locus coeruleus. Eur J Pharmacol 1990;187(3):537-9. 